\title{
Analisis Moral Kerja Pada Dosen
}

\author{
Fatwa Tentama \\ Fakultas Psikologi, Universitas Ahmad Dahlan Yogyakarta, Indonesia \\ Email: fatwa.tentama@psy.uad.ac.id \\ Subardjo \\ Fakultas Hukum, Universitas Ahmad Dahlan Yogyakarta, Indonesia \\ Email: subardjo@law.uad.ac.id
}

(Diterima: 19-April-2019; di revisi: 20-Mei-2019; dipublikasikan: 28-Juni-2019)

\begin{abstract}
Abstrak. Penelitian ini bertujuan untuk menggambarkan moral kerja pada dosen di Universitas "X", menguji validitas konstruk dan reliabilitas konstruk skala moral kerja, mengetahui kontribusi aspek-aspek dan indikator-indikator moral kerja dalam merefleksikan moral kerja dosen, dan menguji model pengukuran skala moral kerja. Metode pengumpulan data dengan menggunakan skala moral kerja. Analisis data dilakukan dengan menggunakan Structural Equation Modeling (SEM) dengan second order confirmatory factor analysis (2nd Order CFA). Hasil analisis menunjukkan Dosen di universitas " $\mathrm{X}$ " memiliki moral kerja dalam kategori tinggi. Aspek dominan yang merefleksikan moral kerja adalah aspek tanggung jawab dengan indikatornya adalah kesanggupan menyelesaikan pekerjaan dan pekerjaan selesai dengan sebaikbaiknya. Aspek paling rendah yang merefleksikan moral kerja adalah semangat kerja dengan indikator kemauan yang mendalam dalam melakukan pekerjaannya dan kesenangan dalam melakukan pekerjaannya.
\end{abstract}

Kata kunci: model pengukuran, moral kerja, 2nd Order CFA

Abstract. This study aims to describe the work morale of the lecturer at the "X" University, to examine the construct validity and construct reliability of the work moral scale, to know the contribution of work morale aspects and indicators in reflecting the work morale of the lecturer, and to test the work moral measurement model. Methods of data collection using the moral work scale. Data analysis was done by using Structural Equation Modeling (SEM) with second order confirmatory factor analysis (2nd Order CFA). The results show that lecturers at university " $\mathrm{X}$ " have morale in high category. The dominant aspect that reflects work morale is the aspect of responsibility with the indicator is the ability to finish the job and the job is done as well as possible. The lowest aspect that reflects work morale is morale with an indicator of willpower in work and pleasure in work.

Keywords: measurement model, work morale, 2nd Order CFA

(1) (8) This is an open access article under the CC BY-NC 4.0 license (http://creativecommons.org/licenses/by-nc-nd/4.0/).

\section{PENDAHULUAN}

Sumber daya manusia merupakan aset yang berharga dalam suatu organisasi yang menjadi perencana, pengatur, dan pelaku aktif dari setiap aktivitas organisasi serta penentu terwujudnya tujuan organisasi (Hasibuan, 2012). Organisasi memerlukan karyawan yang memiliki semangat/gairah, kemauan, kedisiplinan, kerja keras dan tanggung jawab 
untuk bekerja dan berusaha mencapai tujuan organisasi. Hal tersebut tercermin dalam moral kerja karyawan yang dikenal dengan istilah employee moral. Bafadal (2006) semangat atau moral kerja merupakan perwujudankemauan seseorang melalui sikap dan tingkahlakunya dalam bekerja. Moral kerja merupakan suatu iklim atau suasana kerja yang terdapat di dalam suatu organisasi yang menunjukkan rasa kegairahan di dalam melaksanakan pekerjaan dan mendorong untuk bekerja secara lebih baik dan lebih produktif (Nitisemito, 2010). Moral kerja yang tinggi akan tampil berupa kesediaan bekerja keras, tekun dan bergairah, yang secara terus menerus terarah pada pencapaian tujuan organisasi. Moral kerja yang tinggi berpengaruh pada kesediaan mewujudkan cara atau metode kerja yang berdaya guna dan berhasil guna dalam meningkatkan kinerja karyawan. Karyawan yang memiliki moral kerja tinggi akan bekerja dengan penuh antusias, penuh gairah, penuh inisiatif, penuh kegembiraan, tenang, teliti, suka bekerja sama dengan orang lain, ulet, tabah, dan tidak pernah datang terlambat. Karyawan yang memiliki moral kerja rendah akan kurang bergairah dalam bekerja, malas, sering melamun, sering terlambat atau tidak masuk kerja, sering mengganggu, selalu menyendiri, dan sering melakukan kesalahan di dalam melaksanakan tugas (Bafadal, 2006). Dengan kata lain bahwa moral kerja berhubungan dengan sikap seseorang dalam melaksanaakan pekerjaan untuk dapat diterapkannya pengetahuan, keterampilan yang dimilikinya yang didasari atas moral yang baik (Rahayu, 2013). Pentingnya moral kerja tersebut maka perlu diketahui aspek-aspek dan indikatorindikator yang berkontribusi dalam pembentuk variabel moral kerja pada karyawan.

Aspek-aspek moral kerja menurut Pidarta (1988) dan Danim (2004) adalah aspek semangat kerja yaitu suatu kekuatan/kegembiraan, gairah, dan suasana batin yang mendukung dalam bekerja. Seseorang yang mempunyai semangat dalam bekerja akan memiliki kemauan dan kesenangan yang mendalam dalam melakukan pekerjaannya antara lain suasana batin, antusias dan giat dalam bekerja. Suasana batin adalah perasaan senang atau tidak senang, bergairah atau tidak bergairah dan berkemauan keras atau tidak berkemauan keras dalam melaksanakan tugas dan pekerjaannya..

Aspek disiplin merupakan ketaatan, ketepatan waktu dan kesadaran pada aturan dan tata tertib dalam bekerja. Kata moral merupakan kata yang berasal dari bahasa latin 'mores', mores sendiri berarti adat kebiasaan atau suatu cara hidup) berarti sama dengan istilah etika, tetapi dalam praktiknya, istilah moral atau moril telah jauh berbeda dari arti harfiahnya. Moral adalah sikap, semangat dan disiplin pegawai terhadap organisasi dan lingkungan kerjanya. (Umam, 2013). Tanggung jawab dapat dilihat dari kesanggupan seseorang dalam menyelesaikan pekerjaan, selesai dengan sebaikbaiknya, tepat waktu serta berani mengambil resiko.

Penelitian ini bertujuan untuk menggambarkan moral kerja pada dosen di Universitas " $X$ ", menguji validitas konstruk dan reliabilitas konstruk alat ukur yaitu skala moral kerja, untuk mengetahui kontribusi aspek-aspek dan indikator-indikator moral kerja dalam merefleksikan moral kerja, dan mengkonfirmasikan atau menguji model yaitu model pengukuran yang perumusannya berasal dari teori mengenai kecocokan model dengan data.

Confirmatory Factor Analysis (CFA) merupakan salah satu dari pendekatan utama didalam analisis faktor. CFA digunakan untuk menguji dimensionalitas suatu konstruk. Pengujian ini digunakan untuk melakukan pengukuran model (model measurement) sehingga dapat menggambarkan sebaik apa aspek-aspek dapat digunakan sebagai pengukuran variabel laten yaitu moral kerja. Confirmatory Factor Analysis (CFA) juga digunakan untuk menguji validitas dan reliabilitas dari indikator-indikator (item-item) pembentuk konstruk laten (Latan, 2012).

Pada penelitian ini CFA yang digunakan adalah Second order confirmatory factor analysis ( $2^{\text {nd }}$ Order CFA) yaitu model pengukuran yang terdiri dari dua tingkat. Tingkat pertama analisis dilakukan dari konstruk laten aspek ke indikator-indikatornya dan kedua analisis dilakukan dari konstruk laten ke konstruk aspeknya (Latan, 2012). Dengan demikian dapat diketahui moral kerja pada dosen, validitas konstruk dan reliabilitas konstruk skala moral kerja, kontribusi aspekaspek dan indikator-indikator moral kerja dalam merefleksikan/mengukur variabel moral kerja dan mengkonfirmasikan model yang dihipotesiskan yaitu kecocokan model dan data. 
Tentama, Subardjo, Analisis moral kerja... | 35

\section{METODE}

Populasi dalam penelitian ini adalah dosen di Universitas " $X$ " berjumlah 479 orang yang tersebar di seluruh Fakultas di Universitas "X". Ciri-ciri populasi adalah berstatus sebagai dosen tetap di Universitas Muhammadiyah X dan sudah bekerja minimal 1 tahun.

Jumlah sampel penelitian adalah 202 subjek. Teknik sampling yang digunakan dalam penelitian ini menggunakan probability sampling yaitu dengan metode simple random sampling.
Alat ukur yang digunakan untuk mengukur moral kerja dalam penelitian ini adalah skala moral kerja yang dikontruksi berdasarkan pada aspek-aspek moral kerja dari Pidarta (1988) dan Danim (2004) yaitu semangat kerja, disiplin, dan tanggung jawab. Skala moral kerja dibuat dengan menggunakan model skala semantik diferensial yang mempunyai dua bentuk pernyataan yang saling berlawanan dengan bobot skor 1-5. Aspek dan indikator moral kerja dapat dilihat pada tabel 1 . Selanjutya blue print skala moral kerja dapat dilihat pada tabel 2 dibawah ini.

Tabel 1. Aspek dan Indikator Moral Kerja

\begin{tabular}{lll}
\hline No & Aspek & Indikator \\
\hline 1 & Semangat kerja & $\begin{array}{l}\text { a. Kemauan yang mendalam dalam melakukan pekerjaannya } \\
\text { b. Kesenangan (suasana batin) danlam melakukan pekerjaannya }\end{array}$ \\
2 & Disiplin & $\begin{array}{l}\text { a. Ketaatan dan ketepatan waktu pada aturan dan tata tertib } \\
\text { b. Kesadaran pada aturan dan tata tertib }\end{array}$ \\
3 & Tanggung jawab & $\begin{array}{l}\text { a. Kesanggupan menyelesaikan pekerjaan } \\
\text { b. Selesai dengan sebaik-baiknya }\end{array}$ \\
\hline & Total Item &
\end{tabular}

Tabel 2. Blue Print Skala Moral Kerja

\begin{tabular}{|c|c|c|c|c|}
\hline No & Aspek & Indikator & No. Item & $\sum$ \\
\hline \multirow[t]{2}{*}{1} & Semangat kerja & 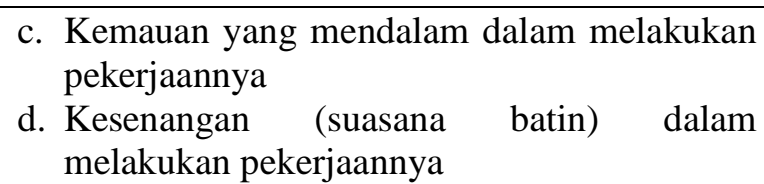 & 2,4 & 2 \\
\hline & & & 1,3 & 2 \\
\hline \multirow[t]{2}{*}{2} & Ketaatan pada aturan & $\begin{array}{l}\text { c. Ketaatan dan ketepatan waktu pada aturan } \\
\text { dan tata tertib } \\
\text { d. Kesadaran pada aturan dan tata tertib }\end{array}$ & 5,6 & 2 \\
\hline & & & 7,8 & 2 \\
\hline \multirow[t]{3}{*}{3} & Tanggung jawab & $\begin{array}{l}\text { c. Kesanggupan menyelesaikan pekerjaan } \\
\text { d. Selesai dengan sebaik-baiknya }\end{array}$ & 9,12 & 2 \\
\hline & & & 10,11 & 2 \\
\hline & Total Item & & & 12 \\
\hline
\end{tabular}

Ket: Uji Validitas Kontruk (Construct Validity) dan Reliabilitas Kontruk (Construct Reliability) dengan Confirmatory Factor Analysis (CFA)

Validitas dan reliabilitas konstruk dari indikator-indikator (item-item) pembentuk konstruk laten dengan melakukan Confirmatory Factor Analysis (CFA) (Latan, 2012). Pengujian validitas dan realibilitas instrumen ini perlu dilakukan agar dalam melakukan penelitian dengan menggunakan analisis faktor konfirmatori didapatkan data yang valid dan reliabel. Dengan kata lain pengujian ini digunakan untuk melakukan pengukuran model (model measurement) untuk menggambarkan sebaik apa aspek-aspek dan indikator-indikator dapat digunakan sebagai pengukuran moral kerja.

Second order confirmatory factor analysis (2nd Order CFA) adalah model pengukuran yang terdiri dari dua tingkat. Tingkat pertama analisis dilakukan dari konstruk laten aspek ke 
indikator-indikatornya dan kedua analisis dilakukan dari konstruk laten ke konstruk aspeknya (Latan, 2012).

Menurut Hair, Black, Babin, dan Anderson (2010), melalui CFA tidak hanya dapat dilakukan pengujian validitas konstrak (Construct Validity), tetapi juga reliabilitas konstruk (Construct Reliability). Hair, Black, Babin, dan Anderson (2010) menyatakan bahwa konstruk mempunyai reliabilitas yang baik adalah jika nilai Construct Reliability (CR) $\geq$ 0,70 dan nilai variance extracted $\geq 0,50$. Berdasarkan 12 item yang terpilih untuk memperoleh besarnya reliabilitas (Construct Reliability) maka digunakan rumus:

$$
\begin{aligned}
& \mathrm{CR}=\frac{\left(\sum \mathrm{SLF}\right)^{2}}{\left(\sum \mathrm{SLF}\right)^{2}+\left(\sum \mathrm{e}\right)} \\
& \mathrm{VE}=\frac{\sum \mathrm{SLF}^{2}}{\sum \mathrm{SLF}^{2}+\left(\sum \mathrm{e}\right)}
\end{aligned}
$$

Keterangan:

CR (Construct Reliability) : Konsistensi suatu pengukuran

VE (Variance Ektracted) : Jumlah varian keseluruhan dalam variabel manifest yang dapat dijelaskan oleh variabel laten

$\sum$ SLF : Jumlah standar loading faktor masingmasing item

$\sum \mathrm{e}:$ Jumlah error masing-masing item

(Hair, Black, Babin, dan Anderson 2010; Wijayanto, 2008)

Metode analisis data dilakukan dengan Structural Equation Model (SEM) menggunakan Linear Structural Model (LISREL) versi 8.71 dari Joreskog dan Sorbom (2008) melalui 2nd Order CFA.

\section{HASIL DAN PEMBAHASAN}

\section{Gambaran Data Penelitian}

Berdasarkan hasil analisis, maka diperoleh gambaran data penelitian pada tabel 3

\begin{tabular}{|c|c|c|c|c|c|}
\hline \multicolumn{6}{|l|}{ Statistics } \\
\hline & Semanga & & Disiplin & Tanggung jawab & Moral Kerja \\
\hline \multirow{2}{*}{$\mathrm{N}$} & Valid & 202 & 202 & 202 & 202 \\
\hline & Missing & 0 & 0 & 0 & 0 \\
\hline Mean & 4,1473 & & 3,9926 & 4,1040 & 4,0813 \\
\hline Median & 4,0000 & & 4,0000 & 4,0000 & 4,0000 \\
\hline Mode & $3,75^{\mathrm{a}}$ & & & 4,00 & 3,83 \\
\hline Std. Deviation & ,55452 & & 65881 & ,59409 & ,50893 \\
\hline Variance & ,307 & & ,434 &, 353 & 259 \\
\hline
\end{tabular}
dibawah ini:

Tabel 3. Statistik Deskriptif Moral Kerja

a. Multiple modes exist. The smallest value is shown

Berdasarkan tabel 3 diperoleh gambaran bahwa data moral kerja subjek diperoleh mean pada aspek semangat kerja sebesar 4,1473, mean pada aspek disiplin sebesar 3,9926 dan mean pada aspek tanggung jawab sebesar 4,1040. Dari data tersebut mean total moral kerja adalah sebesar 4,0813, hal ini berarti bahwa moral kerja dosen di Universitas " $\mathrm{X}$ " terbilang tinggi. Tingginya moral kerja dosen akan menentukan bagaimana dosen bekerja untuk mencapai tujuan universitas. Moral kerja tersebut ditunjukkan dengan semangat bekerja, disiplin kerja dan rasa tanggung jawab dalam bekerja yang tinggi. Hasil penelitian ini sesuai hasil penelitian menurut Rahayu (2013) semangat kerja itu tumbuh dalam diri pegawai yang disebabkan oleh adanya dorongan dari pimpinan agar bekerja dengan baik sesuai dengan aturan dan kebijakan yang berlaku, dorongan tersebut dapat dilihat dari bagaimana cara dalam melaksanakan tugas sehingga tujuan organisasi dapat tercapai.

Pengujian Second Order Confirmatory Factor Analysis (2 $2^{\text {nd }}$ Order CFA). Pengujian $2^{\text {nd }}$ Order CFA ini dilakukan dengan melihat nilai muatan faktor $(>0,5)$ dan nilai t hitung $(>1,96)$. Bobot muatan faktor sebesar 0,50 atau lebih dianggap memiliki validasi yang cukup kuat untuk menjelaskan konstruk laten (Hair, Black, Babin, \& Anderson 2010; Ghozali \& Fuad, 2012). Analisis data dilakukan dengan menggunakan program LISREL dengan melihat nilai muatan faktor $(>0.5)$ dan nilai t hitung $(>1,96)$ yang hasilnya dapat dilihat pada gambar berikut: 


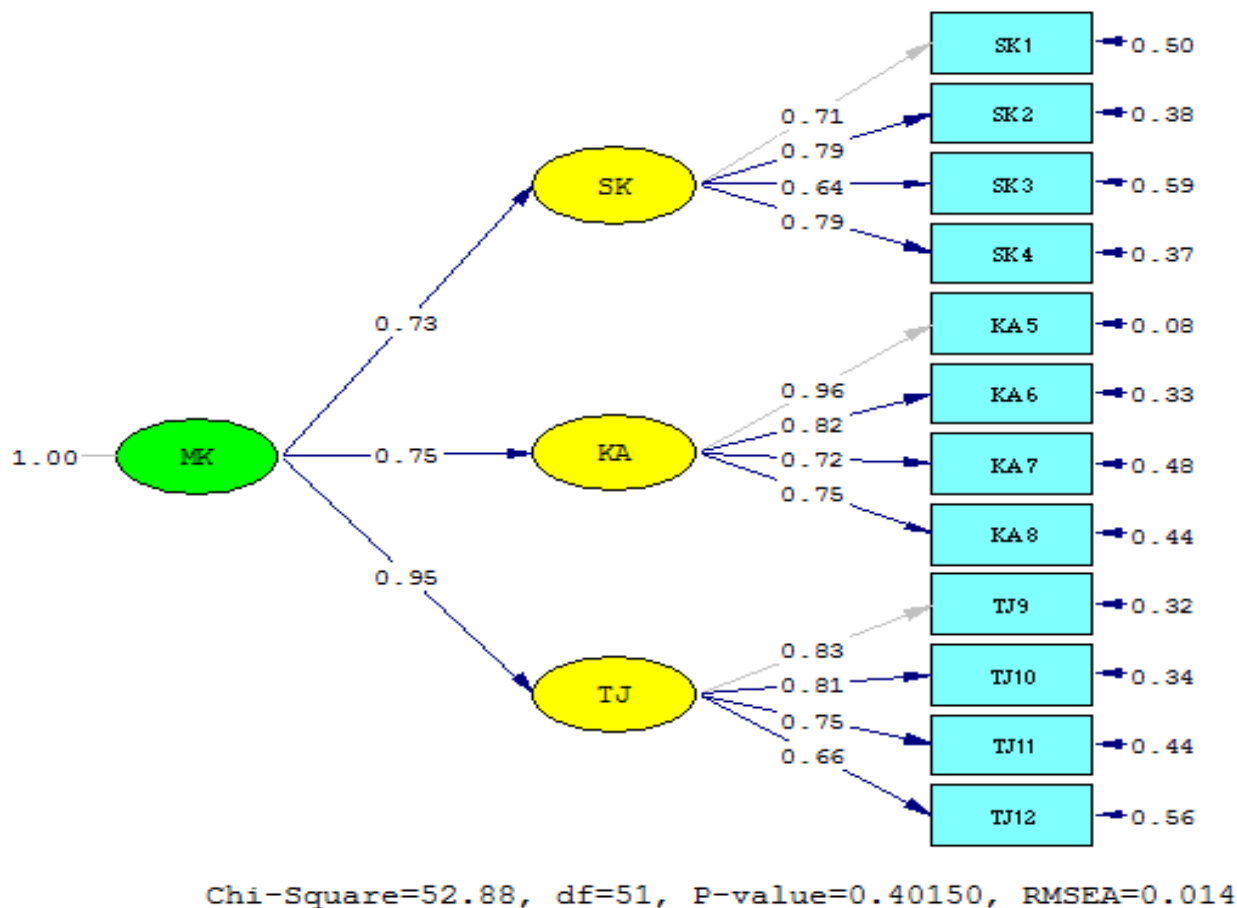

Gambar 1. Muatan Faktor $2^{\text {nd }}$ Order CFA Moral Kerja

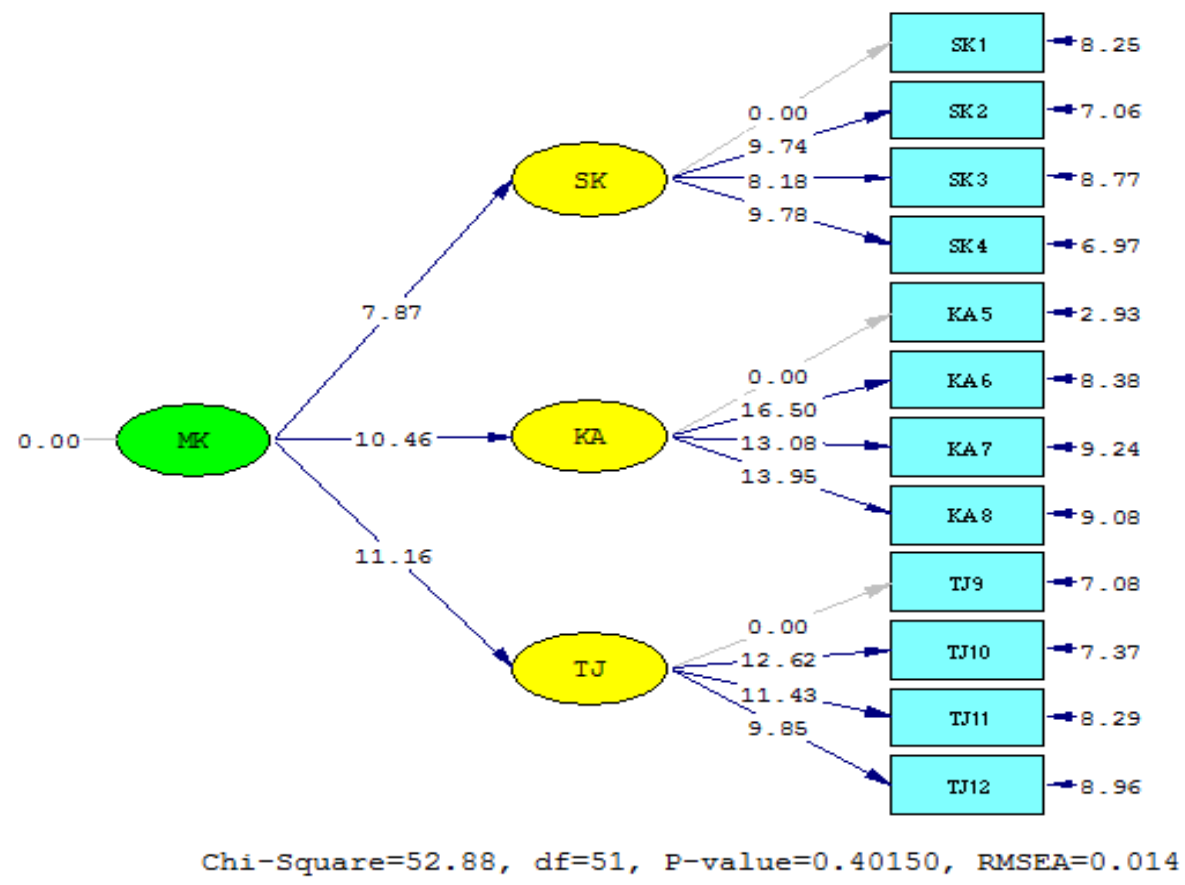

Gambar 2. Nilai-t $2^{\text {nd }}$ Order CFA Moral Kerja

Tingkat pertama analisis dilakukan dari konstruk laten aspek ke indikator-indikatornya. Berdasarkan hasil analisis di atas menunjukkan bahwa nilai loading faktor semuanya lebih besar dari $0,05(>0,5)$ dan semua nilai $t$ hitung yang diperlukan untuk menguji signifikansi nilai loading faktor lebih besar dari 1,96 (>1,96). Hal ini berarti dari 12 item yang mengukur moral kerja tersebut, seluruhnya merupakan item yang valid dan signifikan. Rangkuman hasil tersebut dapat dilihat pada tabel 4 berikut ini: 
Tabel 4. 2nd Order CFA Construct Validity Moral Kerja (Aspek-Indikator)

\begin{tabular}{ccccc}
\hline No. & Item & Muatan Faktor & $\boldsymbol{T}$-Value & Keterangan \\
\hline 1 & SK1 & 0,71 & & \\
2 & SK2 & 0,79 & 9,74 & Sig \\
3 & SK3 & 0,64 & 8,18 & Sig \\
4 & SK4 & 0,79 & 9,78 & Sig \\
5 & KA5 & 0,96 & & Sig \\
6 & KA6 & 0,82 & 16,50 & Sig \\
7 & KA7 & 0,72 & 13,08 & Sig \\
8 & KA8 & 0,75 & 13,95 & Sig \\
9 & TJ9 & 0,83 & & Sig \\
10 & TJ10 & 0,81 & 12,62 & Sig \\
11 & TJ1 & 0,75 & 11,43 & \\
12 & TJ12 & 0,66 & 9,85 & 1 . \\
\hline
\end{tabular}

Tingkat kedua analisis dilakukan dari konstruk laten ke konstruk aspeknya. Berdasarkan hasil pengujian di atas menunjukkan bahwa nilai loading faktor semuanya lebih besar dari $0,5(>0,5)$ dan semua nilai $\mathrm{t}$ hitung yang diperlukan untuk menguji signifikansi nilai loading faktor lebih besar dari 1,96. Aspek semangat kerja (SK) diperoleh muatan faktor 0,73 dengan t hitung 7,87 , aspek ketaatan pada aturan (KA) memiliki muatan faktor 0,75 dengan $t$ hitung 10,46, aspek tanggung jawab (TJ) memiliki muatan faktor 0,95 dengan t hitung 11,16. Rangkuman hasil analisis tersebut dapat dilihat pada tabel 5 berikut ini.

Tabel 5. 2nd Order CFA Construct Validity Moral Kerja (Laten-Aspek)

\begin{tabular}{lllll}
\hline No & Aspek & $\begin{array}{l}\text { Muatan } \\
\text { Faktor }\end{array}$ & T-Value & Ket. \\
\hline 1 & Semangat Kerja & 0,73 & $\mathbf{7 , 8 7}$ & Sig \\
2 & Disiplin & 0,75 & 10,46 & Sig \\
3 & Tanggung Jawab & 0,95 & $\mathbf{1 1 , 1 6}$ & Sig \\
\hline
\end{tabular}

Hasil tersebut menunjukkan bahwa ketiga aspek moral kerja yang terdiri dari semangat kerja, ketaatan pada aturan dan tanggung jawab dikatakan valid dan signifikan untuk mengukur variabel moral kerja. Hasil validitas tersebut didukung juga dengan nilai Chi Square (r) yang menghasilkan nilai 52,88 dengan $p$-value 0,401 $(\mathrm{p}>0,05)$. Hasil penelitian ini sesuai hasil penelitian Rahayu (2013) bahwa moral kerja tinggi dalam mengajar di SMA Negeri Painan, hal ini perlu dipertahankan karena tanpa dilandasi dengan semangat kerja, disiplin kerja, tanggung jawab yang tinggi, maka hasil kerja yang akan di capainya dalam akan melaksanakan tugas akan terlaksana dengan baik.

Berdasarkan rumus perhitungan konstruk reliabilitas diperoleh hasil $\mathrm{CR}=0,95$ dan $\mathrm{VE}=$ 0,6 yang berarti bahwa variabel moral kerja memiliki reliabilitas yang baik. Hair, Black, Babin, \& Anderson (2010) menyatakan bahwa konstruk mempunyai reliabilitas yang baik adalah jika nilai Construct Reliability (CR) $\geq$ 0,07 dan nilai variance extracted $(\mathrm{VE}) \geq 0,40$. 
Tentama, Subardjo, Analisis moral kerja... 3

Tabel 6. Hasil Analisis 2nd Order CFA Cunstruct Reliability Moral Kerja

\begin{tabular}{cccccc}
\hline No & Item & Muatan Faktor & Eror & CR & VE \\
\hline 1 & SK1 & 0,71 & 0,50 & & \\
2 & SK2 & 0,79 & 0,38 & & \\
3 & SK3 & 0,64 & 0,59 & & \\
4 & SK4 & 0,79 & 0,37 & & \\
5 & KA5 & 0,96 & 0,08 & $\mathbf{0 , 9 5}$ & \\
6 & KA6 & 0,82 & 0,33 & \\
7 & KA7 & 0,72 & 0,45 & \\
8 & KA8 & 0,75 & 0,44 & \\
9 & TJ9 & 0,83 & 0,32 & \\
10 & TJ10 & 0,81 & 0,34 & \\
11 & TJ1 & 0,75 & 0,44 & \\
12 & TJ12 & 0,66 & 0,56 & & \\
\hline
\end{tabular}

Selanjutnya untuk kesesuaian modelnya (model fit), secara umum sudah bagus. Adapun kriteria model fit-nya adalah seperti pada tabel 7 berikut:

Tabel 7. Kriteria Model Fit

\begin{tabular}{ccccc}
\hline No & Indeks Fit & Nilai & Nilai Standar & Keterangan \\
\hline 1 & Chi Square $\mathrm{p}$ & $52,88(\mathrm{P}=0,401)$ & $>0,05$ & Fit \\
2 & RMSEA & 0,014 & $<0,08$ & Fit \\
3 & NFI & 0,98 & $>0,90$ & Fit \\
4 & NNFI & 1,00 & $>0,90$ & Fit \\
5 & CFI & 1,00 & $>0,90$ & Fit \\
6 & IFI & 1,00 & $>0,90$ & Fit \\
7 & GFI & 0,96 & $>0,90$ & Fit \\
8 & AGFI & 0,94 & $>0,90$ & Fit \\
\hline
\end{tabular}

Berdasarkan hasil analisis diketahui 8 indeks fit menyatakan bahwa model fit. Hasil ini menunjukkan bahwa model teoritik variabel moral kerja sesuai (fit) dengan data empirik.

Berdasarkan hasil analisis penelitian di atas maka dosen di universitas " $X$ " memiliki moral kerja dalam kategori tinggi. Semua aspekaspek dan item-item yang membentuk moral kerja karyawan dinyatakan valid dan reliabel sehingga semua aspek dan indikator tersebut mampu merefleksikan dan membentuk moral kerja.

Aspek paling dominan yang merefleksikan moral kerja adalah aspek tanggung jawab dimana indikator utamanya adalah kesanggupan menyelesaikan pekerjaan dan pekerjaan selesai dengan sebaik-baiknya. Perilaku spesifiknya adalah dosen bersedia menyelesaikan pekerjaan yang diberikan atasan atau universitas, dosen mampu mengerjakan tugas dengan baik, pekerjaan dapat selesai tepat waktu atau sesuai deadline yang diberikan dan tugas dikerjakan secara maksimal.

Aspek paling rendah yang merefleksikan moral kerja adalah semangat kerja indikator utamanya kemauan yang mendalam dalam melakukan pekerjaannya dan kesenangan (suasana batin) dalam melakukan pekerjaannya tersebut. Perilaku spesifiknya adalah dosen bekerja dengan giat, merasa bangga terhadap pekerjaannya, bekerja dengan rasa gembira dan antusias walaupun lebih rendah aplikasinya daripada aspek disiplin dan tanggung jawab.

Bafadal (2006) menguatkan bahwa moral kerja terwujud dalam bentuk semangat individu dalam bekerja. Dosen yang mempunyai semangat dalam bekerja memiliki kemauan dan kesenangan yang mendalam dalam melakukan pekerjaannya. Adanya perbedaan kemauan dan kesenangan akan menyebabkan pula terjadinya perbedaan sikap dan perilaku kerjanya. Apabila dosen memiliki kemauan yang sungguhsungguh dan kesenangan yang mendalam dalam 
bekerja maka suasana batin dalam bekerja, gairah bekerja, antusias bekerja, kekuatan dan giat dalam bekerja akan terwujud pada dosen.

Menurut (Veithzal, 2010) dimensi dan indikator moral kerja adalah Kesediaan karyawan dalam melaksanakan pekerjaanya seperti, Kepatuhan bekerja, Kemauan menyelesaikan pekerjaan, Keseriusan karyawan saat bekerja, Kesungguhan dalam bekerja. Dosen menunjukkan ketaatan pada peraturan dengan ketepatan waktu dan kesadaran pada aturan dan tata tertib yang berlaku di universitas dan pada akhirnya dosen datang ke kantor lebih awal, tinggi dalam hal kehadirannya dan tidak terjadi keterlambatan maupun absenteism dalam berbagai pekerjaan. Menurut Dwi (2017) maka sudah sepatutnya pimpinan dan segenap mereka yang memegang instansi usaha, bisa dikatan juga merupakan karyawan harus memperlakukan dengan sejawatnya dengan baik,pengolahan kepribadian moral yang baik akan menghasilkan dampak yang baik.

Moral kerja ditunjukkan dengan tanggung jawab dalam bekerja Yusuf (2018) tanggung jawab adalah kesanggupan dalam menyelesaikan pekerjaan yang dibebankan dengan sebaik-baiknya dan tepat waktu pada waktunya serta berani menanggung resiko atas keputusan yang di ambilnya, menunjukkan bahwa factor tanggung jawab berpengaruh secara signifikan terhadap peningktana kinerja pegawai. Dengan demikian dosen yang dapat bertanggung jawab terhadap pekerjaannya dapat memberikan implikasi positif bagi universitas.

\section{SIMPULAN DAN SARAN}

Pengujian dengan Second order confirmatory factor analysis (2nd Order CFA) pada skala moral kerja menunjukkan bahwa skala moral kerja valid dan reliabel sehingga skala moral kerja versi Indonesia bisa dimanfaatkan secara maksimal sebagai alat untuk mengukur mengukur moral kerja pada karyawan. Moral kerja mampu direfleksikan dalam tiga aspek pembentuk moral kerja yaitu semangat kerja, disiplin, dan tanggung jawab. Aspek paling dominan yang merefleksikan moral kerja adalah aspek tanggung jawab dimana indikator utamanya adalah kesanggupan menyelesaikan pekerjaan dan pekerjaan selesai dengan sebaik-baiknya. Perilaku spesifiknya adalah dosen bersedia menyelesaikan pekerjaan yang diberikan atasan atau universitas, dosen mampu mengerjakan tugas dengan baik, pekerjaan dapat selesai tepat waktu atau sesuai deadline yang diberikan dan tugas dikerjakan secara maksimal. Bagi penelitian selanjutnya, peneliti menyarankan untuk memahami sepenuhnya tentang konsep moral kerja dan model konseptual yang digunakan dan peneliti juga mampu untuk memilih model yang tepat agar dapat sesuai dengan kondisi internal subjek atau organisasi. Selain itu dalam menyusun aspek-aspek moral kerja juga perlu memperhatikan aspek budaya dan adat istiadat setempat.

\section{DAFTAR PUSTAKA}

Bafadal, I. (2006). Peningkatan profesionalisme guru sekolah dasar. Jakarta: Bumi Aksara.

Danim, S. (2004). Motivasi kepemimpinan dan efektivitas kelompok. Jakarta: Rineka Cipta.

Davis, K. (1989). Human relation at work. Tokyo: McGraw-Hill Book Company.

Dwi, P, D. (2017). Kajian Kepribadian Moral Para Tenaga Kerja Sebagai Landasan Dalam Pengimplementasian Dunia Kerja. Jurnal Ilmiah Ilmu Administrasi Dan Seketari.

Ghozali I, \& Fuad (2012). Structural equation modeling, teori,konsep dan aplikasi dengan program LISREL8,8. Semarang: Universitas Diponegoro

Hair, J.F., Black, W.J., Babin, B.J., \& Anderson, R.E.. (2010). Multivariate data analysis. Englewood Cliff, NJ: Prentice Hall

Hasibuan, M.S.P. (2012). Manajemen sumber daya manusia. Edisi Revisi. Jakarta: Bumi Aksara.

Joreskog, K. \& Sorbom, D. (2008). Lisrel 7: A guide to the program and applications (2nd edition). Chicago:, Inc.

Kossen, C, J. (2008). Critical interpretive research into the world experience of mature-aged workes marginalised from The Labour Force. A Thesis Submited. Departement of Anthtropology, Archaelogy and Sociology, James Cook University.

Latan, H. (2012). Structural equation modeling konsep dan aplikasi menggunakan LISREL 8,80. Bandung: Alfabeta

McKnight, D. H., Sohel A., \& Roger G. S. (2001). When do feedback, incentive 
control, and autonomy improve morale? The importance of employee-management relationship closeness. (Statistical data included). Journal of Managerial Issues, 13(4), 466-481.

Nitisemito, A. 2010. Manajemen Personalia Manajemen Sumber Daya Manusia. Edisi Ketiga. Ghalia Indonesia. Jakarta.

Pidarta, M. (1988). Peranan kepala sekolah pada pendidikan dasar. Jakarta: Gramedia.
Rahayu, N. (2013). Moral Kerja Guru Dalam Mengajar Di Sekolah Menengah Atas Negeri Painan. Jurnal Administrasi Pendidikan, Vol. 1 Nomor 1, 144-461.

Veithzal, R. 2015. Manajemen Kinerja dan Organisasi. Murai Kencana. Jakarta.

Wijayanto, S.H. (2008). Structural equation mod eling dengan LISREL 8.8. Yogyakarta: Graha Ilmu.

Yusuf, N. (2018) Pengaruh Kepemimpinan, Tanggung Jawab, Kedisiplinan Dan Kerjasama Terhadap Kinerja Pegawai Di Universitas Gorongtalo. Vol. 1-No.1. 